\title{
The Relevance Of Systems Approaches To Integrated Coastal Zone Management Practice In Europe
}

\author{
Jeanette Reis, School of Earth and Ocean Sciences, Cardiff University. \\ Email: reisj@cardiff.ac.uk \\ Tim Stojanovic, School of Geography and Geosciences/Scottish Oceans Institute, \\ University of St.AndrewsEmail: timothy.stojanovic@st-andrews.ac.uk \\ Hance Smith, School of Earth and Ocean Sciences, Cardiff University. \\ Email: smithhd@cardiff.ac.uk
}

\begin{abstract}
SPICOSA ${ }^{1}$, an EU FP6 funded project, running between 2007-2011, has developed a systems approach framework (SAF), to support Integrated Coastal Zone Management (ICZM) practices across 18 study sites in Europe. During the third year of the project, a review was undertaken to assess the relevance of the SAF in theory and in practice. This paper will provide an introduction to the SPICOSA project and set the context with a review of European ICZM capacity building activities. It will then summarise some of the key steps involved in developing a systems approach framework before considering developments in practice. Discussion will focus on the review of 4 of the 18 study sites, and in particular:

a) how a systems approach has assisted implementation of ICZM Principles

b) whether a systems approach has assisted strategic management of coastal zones

c) which aspects of a systems approach have been most useful in facilitating technical management of coastal zones

d) capacity for action of stakeholders

e) limitations of systems approaches in ICZM practices.
\end{abstract}

The paper will conclude with an overview of lessons learned from the SPICOSA experience and consideration of how systems approaches have the potential to positively influence ICZM practices in the future.

Key words: systems approaches, integrated coastal zone management, capacity building.

\section{Introduction: EU ICZM Capacity Building}

EU activities related to ICZM have gained momentum in recent years. Following on from research into ICZM capacity requirements $\left[{ }^{1}\right]$, there has been an evaluation of the extent of EU ICZM implementation $\left[{ }^{2},{ }^{3}\right]$ policy frameworks such as the ICZM Strategy $\left[^{4}\right]$, EU Communication $\left[{ }^{5}\right]$, EU ICZM recommendation [6], and the development of a Green Paper $\left[{ }^{7}\right]$ and Blue Book $\left[{ }^{8}\right]$ on integrated maritime policy.

Although there remains a disparity between EU ICZM activities and those of other developed nations, a number of short-term ICZM capacity building projects have begun to close the gap. These include the EU Demonstration Programme (1996-1999), COREPOINT (2004-2008), ENCORA (2006-2009), IMCORE (20082011) and SPICOSA (2007-2011).

\section{Introduction: Science Policy Integration for Coastal Systems Assessment}

${ }^{1}$ http://www.spicosa.eu 
The SPICOSA EU FP6 funded project has developed in response to the need for greater engagement between scientific researchers and those involved in policy and decision-making in coastal zones of Europe. The 250+ project partners are drawn from 54 institutions in 21 countries with representatives from the natural, economic and social sciences $\left[{ }^{9}\right]$. The goal of the project is to develop an operational research framework, which will enable the integration of social, economic and ecological assessments. It is envisaged that this will deliver prognostic estimates of complex coastal systems. Decision-support tools and training programmes are also being developed so that the outputs of this approach can be cascaded to managers and policy makers in an adaptable and user friendly way. During the project, this research framework is being tested in 18 study sites around European coasts. This paper presents a preliminary review of the relevance of a systems approach framework (SAF), particularly in the context of ICZM, in four of those study sites.

\section{Methodology: Systems Approach Framework (SAF)}

Scientific methodology has traditionally relied upon reductionist approaches to isolate phenomena for investigation. However, many of the current real-world sustainability issues faced by society involve complex chains of interactions permeating through natural and man-made systems and ranging from global right through to local scales. This has led to a call for more interdisciplinary and multidisciplinary approaches to scientific investigation focused around real-world problems, termed sustainability science $\left.{ }^{10}\right]$. Current challenges involve developing methodologies to implement these interdisciplinary approaches and in particular, overcoming difficulties associated with: lack of engagement between scientists and practitioners, lack of data, uncertainty, contrasting terminologies, and integrating results from a broad spectrum of methodologies and disciplines $\left[{ }^{11},{ }^{12},{ }^{13}\right]$.

A systems approach is a way of conceptualising the components of a system, in the case of SPICOSA, the coastal zone system. The SPICOSA Systems Approach Framework (SAF) takes account of the interconnectedness of physical and socio-economic component parts of the coastal zone system $\left[{ }^{14}\right]$ and draws on various methodologies and disciplines to consider these dynamic interactions using a range of review, modelling and visualisation tools. Figure 1 illustrates the key steps involved in implementing the SAF.

Figure 1: Key Steps of the SAF

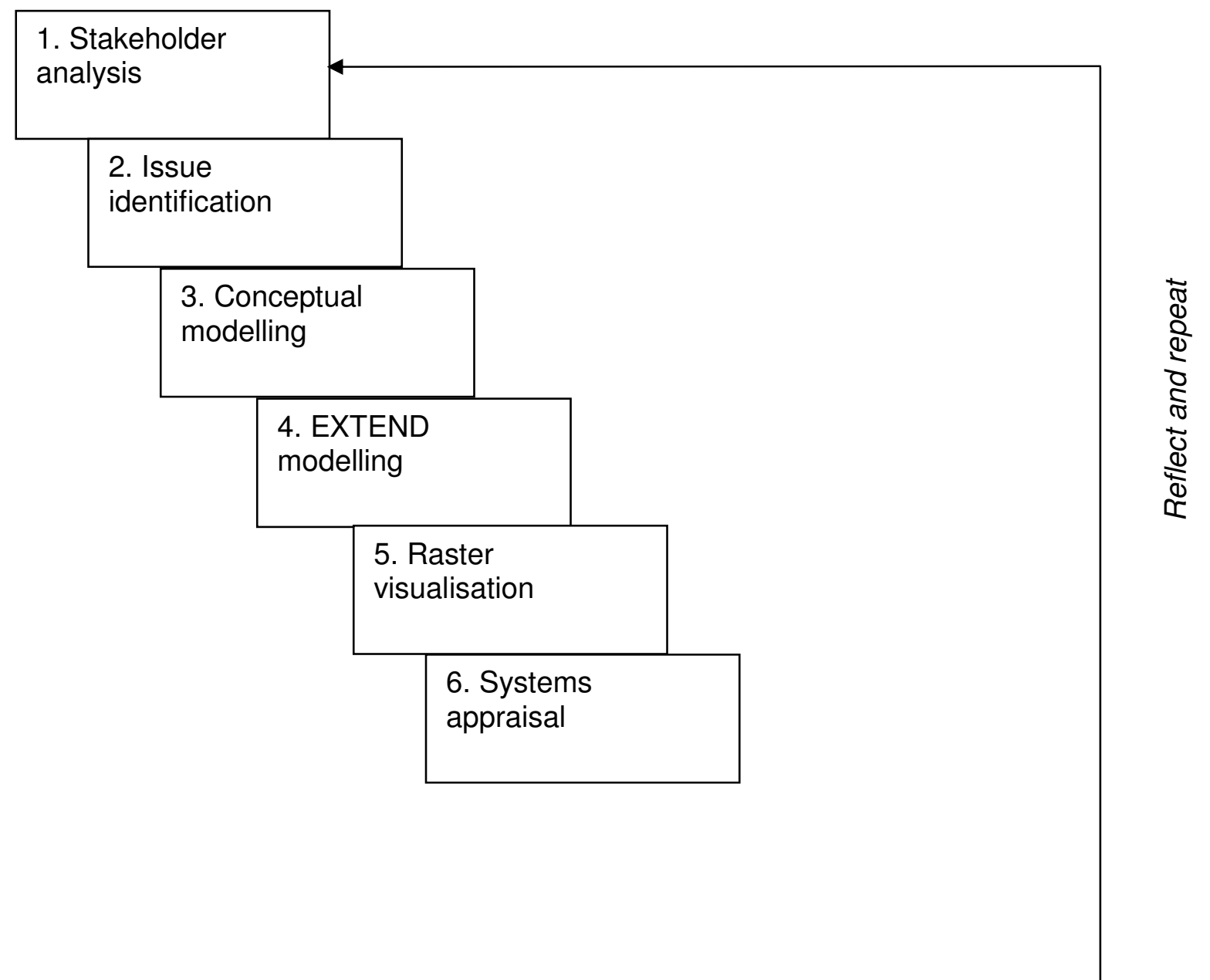




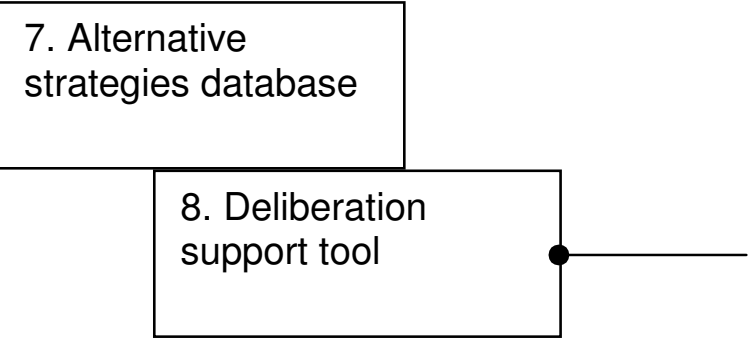

\section{Case Study Sites}

Table 1 describes four study sites, from which scientists developing the SAF were interviewed for this research. Each site has focussed on a different research issue and involved a variety of coastal stakeholders, depending on the context. This paper makes an assessment of the outputs of the systems approach framework, especially considering how the scientific analysis contributes to, or is of value to, managers and policymakers. This is tested at three levels: firstly the level to which the approach supports integration in coastal management, secondly the applicability of the approach in achieving policy goals, and thirdly the usefulness of the approach in conducting technical assessments in the coastal zone.

Table 1: Selected SPICOSA Study Sites

\begin{tabular}{|l|l|l|l|l|c|}
\hline & Country & Area & $\begin{array}{l}\text { Coastal } \\
\text { Typology }\end{array}$ & $\begin{array}{l}\text { Research } \\
\text { Issue }\end{array}$ & $\begin{array}{l}\text { Pre- } \\
\text { existing } \\
\text { ICZM } \\
\text { Initiative }\end{array}$ \\
\hline $\begin{array}{l}\text { Scheldt } \\
\text { Estuary }\end{array}$ & $\begin{array}{l}\text { Netherlands/Bel } \\
\text { gium }\end{array}$ & $\begin{array}{l}22000 \\
\text { sq km }\end{array}$ & $\begin{array}{l}\text { Large industrialised } \\
\text { estuary }\end{array}$ & $\begin{array}{l}\text { Water Quality: } \\
\text { ecological health }\end{array}$ & No \\
\hline Cork Harbour & Ireland & $\begin{array}{l}1200 \\
\text { sq km }\end{array}$ & Natural Harbour & $\begin{array}{l}\text { Coastal } \\
\text { Development }\end{array}$ & Yes \\
\hline $\begin{array}{l}\text { Barcelona } \\
\text { Waterfront }\end{array}$ & Spain & $\begin{array}{l}5 \\
\text { sq km }\end{array}$ & Open Coast & $\begin{array}{l}\text { Microbiological } \\
\text { Water Quality }\end{array}$ & No \\
\hline $\begin{array}{l}\text { Guadiana } \\
\text { Estuary }\end{array}$ & Portugal/Spain & $\begin{array}{l}30 \\
\text { sq km }\end{array}$ & Estuary & $\begin{array}{l}\text { Water } \\
\text { Resources: } \\
\text { Pollution and } \\
\text { Sediment Quality }\end{array}$ & No \\
\hline
\end{tabular}

\section{Results}

\subsection{ICZM Principles}

Integrated Coastal Zone Management has developed in response to the perceived shortfalls of sectoral management and the need for a holistic approach to the management of the coast. In Europe, the current focus is arguably on 'principles' of good management $\left[{ }^{15}\right]\left[{ }^{16}\right]\left[{ }^{17}\right]$, encouraging approaches which are more holistic, participatory, long-term and adaptive. Whilst the SAF study sites were not ICZM projects themselves, they aimed to develop science which could integrate with such an approach. Two of the four study sites reviewed had a pre-existing ICZM group, although all sites agreed that no single authority was responsible for 
ICZM and that the remits and hierarchies of organizations involved were complex and confusing. (The lack of clarity about which organisations are responsible for which activities, was particularly amplified at cross-border study sites). In those study sites where there were pre-project ICZM activities, this provided a platform for engagement with practitioners and exploration of SAF results. Overall, it is concluded that certain elements of effective ICZM practice have been positively influenced by the SPICOSA SAF. The SAF is particularly supportive of improving comprehensive understanding of marine and terrestrial interactions; improving understanding about sustainability trajectories; using long term environmental cycles and improving cooperation. More specifically:

- three sites of the four confirmed that there is a better understanding of marine and terrestrial interactions after undertaking the SAF;

- three sites confirmed that SAF activities have improved understanding about sustainability trajectories;

- three sites used long term environmental cycles, but all acknowledged that it is difficult to incorporate long term economic cycles;

- co-operation has been improved at all study sites, including that between scientists and stakeholders, but also between different groups of scientists across disciplinary boundaries.

The important contribution of the SAF is in providing a methodology which supports these approaches, rather than simply assenting to the principles of ICZM but taking no practical action.

\subsection{Strategic Management}

A profusion of legislation and policy related to the coastal zone has developed in Europe over the last few decades $\left[{ }^{18}\right]$. EC Directives have been a major driver for undertaking assessments in the coastal zone. For example, the Water Framework Directive (2000/60/EC) and Marine Strategy Framework Directive (2008/56/EC) require assessment of the ecological or environmental status of marine waterbodies and improvements in water quality. All of the case study coastal zones have Natura 2000 conservation designations under the Habitats Directive (92/43/EEC) for all or part of their sites. Where developments occur in these sites, they are likely to require some assessment of the deterioration or disturbance of natural habitats and species.

Three of the study sites reported that SPICOSA activities directly contributed towards assessing ecosystem health. In the Scheldt case, the SAF was utilised to support the Water Framework Directive and related Urban Waste Water Treatment Directive (91/271/EEC), by considering inputs of nitrogen and the potential for algal blooms. In the Guadiana case, links between ecological and socio-economic systems were considered relative to the microbiological water quality standards of the Bathing Waters Directive (2006/7/EC). Likewise, the Barcelona case considered bathing water quality as one amongst many factors in sustainable beach use. The Guadiana case was also relevant to the requirements of the Environmental Impact Assessment Directive (as amended 97/11/EC) and the Strategic Environmental Assessment Directive (2001/42/EC) in considering the impact of waste water treatment plants and regional planning. In the Cork site, the assessment of marine recreation development was important for the development of spatial planning policy. The strength of a systems approach in such cases is the ability to make a prognostic assessment of different elements of the coastal zone. However, despite the advantages of a systems methodology, the level of scientific uncertainty may remain high- accordingly, the following section of the paper goes on to consider the technical aspects of assessment.

\subsection{Technical Management}


Technical management refers in this sense to the professional practices, information assessment and information management activities considered in Smith and Vallega's Sea Use Matrix $\left[{ }^{19}\right]$. These include, for example, planning practices, law, monitoring and surveillance activities.

Interviewees were asked to consider the contribution of the key SAF activities in supporting ICZM technical management processes. The key SAF activities included: stakeholder analysis, issue identification, conceptual modelling, EXTEND modelling, raster visualisation, systems appraisal, use of the alternative strategies database and use of the deliberation support tool (see Figure 1).

Stakeholder analysis involves identification of key stakeholder and review of how they relate to one another. In many cases, stakeholder analysis was undertaken for the first time via the SPICOSA project, and although a relatively new activity, it was agreed by all study sites (Cork, Barcelona, Scheldt and Guadiana) to be a useful exercise which was relevant for supporting effective ICZM practice.

Once stakeholders had been identified, SSA teams were asked to agree on an issue of relevance. Following extended deliberations, SSAs were steered by the project team to select an ecological issue which had economic and social implications. The majority of study sites chose water quality as their issue, although the associated economic and social characteristics tended to vary from site to site. It is notable that one of the study sites (Guadiana) reported that fuzziness of issues is often more of a political, rather than a real issue. By exploring relationships between stakeholders, and between stakeholders and the issues they are directly involved with, it has become possible to differentiate between real and "fuzzy" issues, and hence to prioritise real issues where appropriate.

Identification of an issue was a challenging task for many SSAs, as it was difficult to pinpoint a theme which had ecological, social and economic characteristics, which also had expert representation and available, appropriate data. Bias was also exerted, as the majority of scientists involved in the project were ecologists, therefore there were challenges in raising awareness and gaining engagement from other academic disciplines.

The next step involved conceptual modelling. Conceptual modelling involves drafting a hand drawn or computer-based diagram (C-Map was used by many sites) of the ecological, social and economic "system" being reviewed, including key processes, relationships and influencing factors. Following detailed discussions and sharing of knowledge and experiences, this platform presented the joint perspectives of stakeholders involved. Similarly to stakeholder identification, this was the first time many SSAs had seen a graphic representation of their system and many were surprised at how simple and useful this exercise was. Being able to conceptualise and communicate inter-relationships of the system to non-experts was reported to be particularly beneficial to ICZM practices.

EXTEND modelling took conceptual modelling to the next level and involved dynamic modelling and detailed data analysis. Some study sites were undecided about the usefulness of EXTEND modelling, and although potentially a powerful tool, EXTEND modelling requires training and development of expertise, specific commercial software, high specification computer hardware and a great deal of data. In addition, the majority of SSAs reported incomplete or unreliable data, therefore the accuracy of model outputs was questionable. However the modelling process itself can be helpful in building deeper understanding of coastal systems, of positive and negative feedback loops, systems blockages, and node points.

Although graphic visualisation was a potential tool in the SPICOSA toolbox, it was not used by most SSAs. There were various reasons for this, including lack of expertise to link EXTEND modelling software with the raster visualisation software and lack of demonstrations on how it could be used. However, two SSAs (Scheldt and Guadiana) could see potential and expressed an interest in exploring how it could be applied in their areas. 
The systems appraisal step involved a review of the modelled system, to ensure accuracy and fair representation of reality. There was no consensus over the usefulness of the systems appraisal step, possibly because interviews were held too early in the project (a year before the end). Although, not really explored to full potential as part of project activities at the time of review, appraisal is an important aspect of any capacity building activity because it acts as "an anchor" for new conceptual and planning developments and ensures they are realistic and achievable.

Alternative management strategies should always be considered as an integral part of any ICZM process. In reality, there is rarely an ideal solution to a problem and awareness of other approaches, whether in isolation or as a suite of responses, usually leads to more sustainable outcomes. An alternative strategies database was developed as part of the SAF, although most study sites identified and explored their own alternative strategies during conceptualisation and modelling stages.

Once agreement has been reached on who the key stakeholders are, what the main issue is, how it is influenced by internal and external factors, and which potential solutions should be considered, it is appropriate to make use of a tool to assist deliberations. The Deliberation Support Tool (DST) facilitated decision-making by setting out a number of management options and collating and summarising responses in a straightforward, easy to understand way. The majority of study sites agreed that the DST was useful for ICZM, particularly as it provided a focus for activities to date, and facilitated the evolution of the decisionmaking process from a theoretical to a practical application.

In summary, it is concluded that stakeholder analysis, conceptual modelling and the deliberation support tool were found to be the most useful aspects of the SAF. In addition, and as an unintended consequence of the SAF process, two study sites confirmed that the approach to technical assessment had changed as a result of learning about systems approaches. One site reported that the SAF had introduced economic aspects to technical management practices for the first time and had improved beach user accounting methodologies and another reported that timescales for observation had been extended as it had been aware of the need for long-term monitoring through project experiences.

\section{Discussion}

\subsection{Capacity for Action and Capacity Building}

Capacity for implementing a systems approach involves resources in the form of capital, expertise, skills, data and knowledge. Initial capital was required to fund personnel to co-ordinate local activities. Scientific and management expertise was required to develop conceptual maps of local systems and skills in modelling, supported by local knowledge and data were required to develop detailed EXTEND models. Together, these activities delivered a systems approach in a local context. The level of capacity varied between study sites, although the majority confirmed that they had adequate resources to participate fully in the project.

Additional capacity has been developed through the practices of sharing knowledge, skills and attitudes between academic disciplines and between study sites, although this has been limited to SPICOSA partners. Capacity has also been developed via the process of learning a new approach and developing new multidisciplinary skills to implement this approach effectively, again mainly limited to project partners. However, cascade activities through WP10 Communication, WP12 and WP13 (Education and Professional Training workpackages respectively), and in particular through SETNET (SPICOSA Education and Training Network) newsletters and website activities have been slightly more effective at building capacity beyond the immediate project community.

\subsection{Limitations of Systems Approaches in ICZM Practices}


Overall, it is fair to say that interviewees felt positive about the systems approach experience and had developed an insight into the potential contribution of systems approaches in the wider ICZM context. Constructive criticism focussed upon the need to involve more stakeholders, to develop a common glossary, the potential usefulness of a pilot site, the role of data appraisal, the use of modelling in the first cycle and the use of common denominators for modelling.

It can be challenging to ensure there are enough stakeholders and that enough perspectives are included to ensure fair representation of the system. Having said this, if too many stakeholders are involved, it can be more difficult to gain consensus and the system being mapped will significantly grow in size as more people contribute to it. Related to the involvement of stakeholders is the role of communication, and in particular, use of language between those stakeholders. The language associated with scientific disciplines is often specific to that specialism and when multidisciplinary activities take place, it is essential to develop a common glossary that all partners can use and refer to. An example from the project was the use of the term "value". To social scientists, this can refer to the degree to which a person appreciates something eg. "I value my freedom", however, to an economist, this can refer to the cost or price of a unit eg. " 5 Euros per kilogramme". The challenge of communicating across disciplines led to a glossary being developed in the latter stages of the project. Subsequent discussions have concluded that such a glossary would have been most beneficial if developed during preliminary stages of the project.

In addition, it was concluded that use of a pilot site during preliminary project stages would have allowed lessons to be learned about stakeholders, tools, techniques and data. It is considered that this would have made the process of applying a systems approach much more straightforward and less experimental. One partner also discussed the need to appraise data before selecting a study site and issue, as full implementation of the systems approach framework is heavily dependant on availability of good data sets.

The EXTEND modelling activities associated with the systems approach framework were a contentious area for some study sites. Some reported that it was a useful activity while others concluded that the same results could be achieved using concept diagrams. This was mainly a result of the lack of data, the level of uncertainty associated with the data and the time and resource implications of developing a working model. Those study sites that were supportive of the use of modelling suggested that perhaps it would be more appropriate to omit modelling in the first cycle, and instead develop it in detail during the second cycle. The same group also suggested developing common denominators for modelling, so that time could be saved in developing software routines and results could be more easily compared across study sites.

\section{Conclusions:}

In conclusion, it can be demonstrated that systems approaches have the potential to positively influence ICZM. Even though results of modelling can be questionable, the process of raising awareness of roles and responsibilities of stakeholders, of identifying influencing factors and of gaining consensus on what the system "looks like" is valuable in itself. Being able to illustrate and communicate complex economic, social and ecological concepts on a single, easy to understand platform is also valuable, particularly when bringing different scientific disciplines together or when attempting to close the gap between science and policy.

And so, what challenges remain? It takes time for new ideas and concepts to embed themselves into professional practice, and although a significant proportion of current coastal academics and a limited number of coastal management professionals have, "tried out" the systems approach in a "safe environment", the next 
generation of coastal managers are only just beginning to hear about systems approach experiences. It is essential that the message about the potential usefulness of systems approaches continues to be cascaded, and it is planned that this will continue beyond the life of the project via education and training activities.

\section{Acknowledgements}

The authors would like to thank EU FP6 for funding the SPICOSA project. We would also like to thank SPICOSA partners for their input to this review and Tara Thrupp of Cardiff University for her contribution in collating responses for this paper.

\section{References}

${ }^{1}$ Cicin-Sain B, Knecht R.W, Vallega A and Harakunarak A, 2002. Education and Training in Integrated Coastal Management: Lessons from the International Arena. Ocean and Coastal Management. 43 (4) (2002), pp. 291-330

${ }^{2}$ Rupprecht Consult- Forschung and Beratung GmbH. 2006. Evaluation of Integrated Coastal Zone Management in Europe: Final Report revised version 1/12/06 (2006)

${ }^{3}$ European Commission. 2007. Communication from the Commission - Report to the European Parliament and the Council: an Evaluation of Integrated Coastal Zone Management (ICZM) in Europe. COM/2007/0308 final (2007)

${ }^{4}$ European Commission. 1999. Towards a European Integrated Coastal Zone Management Strategy: General Principles and Policy Options. Luxembourg: Office for Official Publications of the European Communities (1999), 32 pp.

${ }^{5}$ European Commission. 2000. Communication from the Commission to the Council and the European Parliament on Integrated Coastal Zone Management: a Strategy for Europe (COM/2000/547), adopted 27 September, (2000).

${ }^{6}$ European Parliament and Council. 2002. Recommendation of the European Parliament and of the Council of 30 May 2002 Concerning the Implementation of Integrated Coastal Zone Management in Europe (2002/413/EC) OJ L148.

Official Journal of the European Communities; (2002), 24-27

${ }^{7}$ European Commission. 2006. Green Paper "Towards a Future Maritime Policy for the Union", COM(2006) 275 final, 7.6.2006

${ }^{8}$ European Commission. 2007. The Blue Book - An Integrated Maritime Policy for the European Union. Commission of the European Communities, Brussels (2007)

${ }^{9}$ SPICOSA. 2007. Description of Work. Document Produced for the EU FP6 Funded SPICOSA Project.

${ }^{10}$ Kates RW, Clark WC, Corell R, Hall JM, Jaeger CC, Lowe I, et al. 2001. Environment and Development: Sustainability Science. Science 292 (5517), 641-2.

${ }^{11}$ Kohn J. and Gowdy J., 1999. Coping with Complex and Dynamic Systems. An Approach to a Transdisciplinary Understanding of Coastal Zone Developments. Journal of Coastal Conservation 5, 163-170

${ }_{12}$ Turner RK. 2000. Integrating Natural and Socio-Economic Science in Coastal Management. Marine Systems. 447460.

${ }^{13}$ Stojanovic T.A., Ball I., Ballinger R.C., Lymbery G. and Dodds W. 2009. The Role of Research Networks for SciencePolicy Collaboration in Coastal Areas. Marine Policy. 33, 901-911.

${ }^{14}$ Van der Weide J., 1993. A Systems View of Integrated Coastal Management. Ocean and Coastal Management. 21, 129-148.

${ }^{15}$ European Parliament and Council, 2002. Recommendation of the European Parliament and of the Council of 30 May 2002 Concerning the Implementation of Integrated Coastal Zone Management in Europe (2002/413/EC_OJ L148. Official Journal of the European Communities; $24-27$.

${ }^{16}$ McKenna J., Cooper A. and O'Hagan A.M., 2008. Managing by Principle: A Critical Analysis of the European

Principles of Integrated Coastal Zone Management (ICZM) Marine Policy 32, 941-955.

17 Stojanovic T. and Ballinger R.C., 2009. Integrated Coastal Management: A Comparative Analysis of Four UK Initiatives Applied Geography, 29, 49-62.

${ }_{18}$ Ballinger R.and Stojanovic T., 2010. Policy Development and the Estuary Environment: A Severn Estuary Case study Marine Pollution Bulletin, 61, 132-145.

${ }^{19}$ Smith H.D., and Vallega A., 1991. The Development of Integrated Sea Use Management. Routledge. pp 283. 